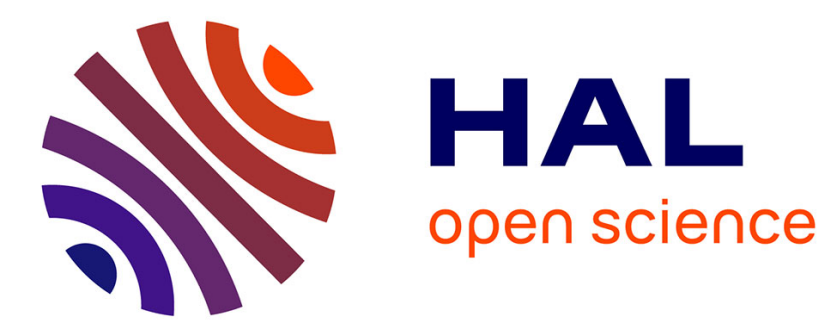

\title{
Nanoparticles in direct-current discharges: Growth and electrostatic coupling
}

K. Kishor Kumar, Lénaïc Couëdel, Cécile Arnas

\section{To cite this version:}

K. Kishor Kumar, Lénaïc Couëdel, Cécile Arnas. Nanoparticles in direct-current discharges: Growth and electrostatic coupling. Journal of Plasma Physics, 2017, 80, pp.849 - 854. 10.1017/S0022377814000439 . hal-01451152

\section{HAL Id: hal-01451152 \\ https://hal.science/hal-01451152}

Submitted on 31 Jan 2017

HAL is a multi-disciplinary open access archive for the deposit and dissemination of scientific research documents, whether they are published or not. The documents may come from teaching and research institutions in France or abroad, or from public or private research centers.
L'archive ouverte pluridisciplinaire HAL, est destinée au dépôt et à la diffusion de documents scientifiques de niveau recherche, publiés ou non, émanant des établissements d'enseignement et de recherche français ou étrangers, des laboratoires publics ou privés. 


\title{
Nanoparticles in direct-current discharges: growth and electrostatic coupling
}

\author{
Kishor Kumar K. ${ }^{1,2}$ AND L. Couëdel ${ }^{1}$ AND C. Arnas ${ }^{1} \dagger$ \\ ${ }^{1}$ Laboratoire de Physique des Interactions Ioniques et Moléculaires, \\ CNRS, Aix-Marseille Université, Marseille, France \\ ${ }^{2}$ Current address: Center for Plasma-Material Interactions (CPMI), \\ University of Illinois, Urbana, USA
}

(Received 10 June 2014)

The formation of nanoparticles from the sputtering of graphite and tungsten cathodes in direct-current discharges is investigated. The successive phases of growth present specificities according to the cathode material. The evolution of the discharge and plasma parameters during the growth phases accounts for the nanoparticle-plasma electrostatic coupling. This evolution also presents strong differences as a function of the cathode material. Features characterising each case are discussed.

\section{Introduction}

Low temperature plasmas can generate nanoparticles (NPs). Many studies were devoted to their formation, especially in $\mathrm{SiH}_{4}$-based discharges relevant for plasma processing (Boufendi et al. 1992; Watanabe 2006). The formation of carbon NPs has also been investigated from sputtered carbon atoms (Ganguly et al. 1993; Praburam \& Goree 1995; Samsonov \& Goree 1999a) and in hydrocarbon plasmas (Deschenaux et al. 1999; GéraudGrenier et al. 2004; Kovačević et al. 2005). All these studies were mainly performed in high-frequency discharges. In addition, few studies have been devoted to the generation of metallic nanoparticles (Jellum \& Graves 1990; Samsonov \& Goree 1999b) and to comparisons between various growth mechanisms. Therefore, we report on the NP formation from the sputtering of graphite and tungsten cathodes in parallel electrode direct-current (DC) discharges (Arnas et al. 2013; Kishor Kumar et al. 2013). Specific growth sequences as well as strong differences of the evolutions of plasma and discharge parameters are presented as a function of cathode materials.

\section{Experimental set-up}

DC discharges are produced between two parallel electrodes (Arnas \& Mouberi 2009). The cathode of $10 \mathrm{~cm}$ diameter placed at the top of the device, is in graphite or tungsten. The grounded anode of $15 \mathrm{~cm}$ diameter is in stainless steel. Both electrodes are separated by $10 \mathrm{~cm}$. Discharges are produced in argon at the pressure of $60 \mathrm{~Pa}$. The current densities are fixed at $10 \mathrm{~A} \cdot \mathrm{m}^{-2}$ and $5 \mathrm{~A} \cdot \mathrm{m}^{-2}$ for respectively graphite and tungsten cathodes, in order to have calculated sputtered carbon and tungsten fluxes of the same order, $\Gamma \sim 10^{18} \mathrm{~m}^{-2} \mathrm{~s}^{-1}$. In such conditions, NPs are generated in the plasma, which consists mainly of a negative glow. During the growth, evolutions of the discharge voltage, plasma density and emission line intensities are recorded. NPs are then collected on substrates, pushed one after the other under a hole, drilled in the anode center. Samples are analysed

$\dagger$ Email address for correspondence: cecile.arnas@univ-amu.fr 

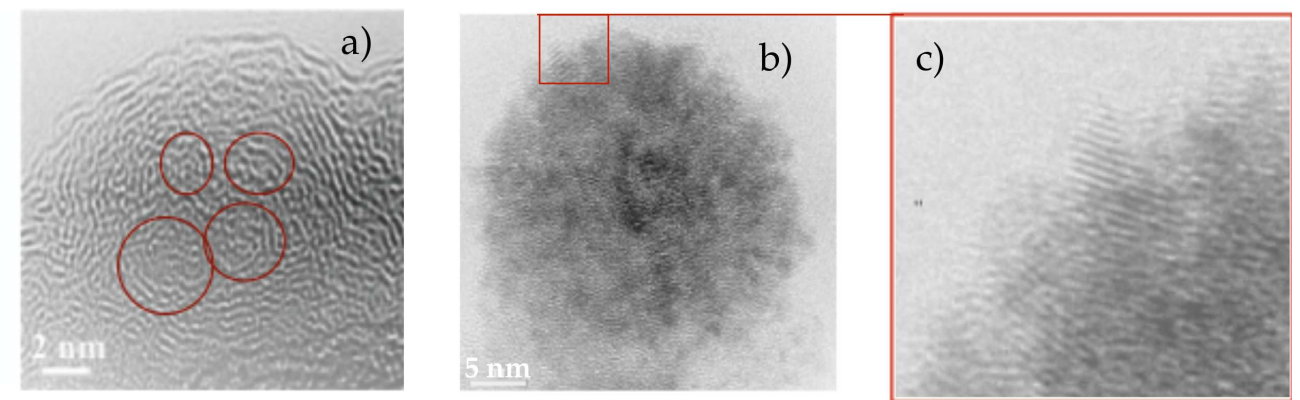

FiguRE 1 . at $\mathrm{t}=60 \mathrm{~s}$, a) carbon nanoparticle grown by coagulation of nuclei $(2-3 \mathrm{~nm})$, welded by graphitic domains, b) tungsten nanoparticle grown by coagulation of crystallites (3-4 nm), c) magnification of tungsten crystallites on the nanoparticle edge.

by electron microscopy for size measurements and internal structure studies (Dominique \& Arnas 2007). The NP detection in the plasma is performed by laser scattering (Zeinert et al. 2008).

\section{Nanoparticle formation}

It is admitted that NP precursors are negative ion clusters. They grow through complex chemical reactions in the plasma where they are trapped up to the nucleation i.e. the appearance of the first solid particles of 1-3 nm. The latter coagulate to form spheroid particles also called primary particles. Modellings show that because of charge fluctuations the probability for small particles to be neutral or positively charged is not strictly equal to zero and can thus favoured coagulation (Matsoukas 1997). In a self-consistent model of the particle charging process in a plasma, it was also shown that the probability to have positively charged small particles is enhanced when the electron density decreases while the big particles stays highly negatively charged. This result indicates that the coagulation mechanism is also favoured by size dispersions because attraction between small and big particles is favoured (Annaratone et al. 2009). When the nucleation diminishes, this mechanism saturates and the NP growth continues by ionic and/or neutral species deposition.

Figure 1-a) shows a carbon NP of $\sim 15 \mathrm{~nm}$, grown by coagulation of nuclei of 2-3 nm. Carbon deposits, appearing in the shape of graphitic domains, weld these nuclei. Figure 1 -b) shows a tungsten NP of $\sim 30 \mathrm{~nm}$, grown by coagulation of crystallites of $2-4 \mathrm{~nm}$, identified by parallel diffraction fringes in figure 1-c). Size histograms were established for various plasma durations. Figure 2 shows the size increase between $10 \mathrm{~s}$ and $300 \mathrm{~s}$, in blue (black) of carbon (tungsten) NPs. The dots are the average sizes and the vertical bars, the multiplicative standard deviations of size histograms, fitted by lognormal functions. In both cases, the fastest sequence corresponds to a growth by coagulation. Beyond $t>200 \mathrm{~s}$, the coagulation of carbon NPs saturates. During this saturation phase and for $\mathrm{t}>400 \mathrm{~s}$, a new NP generation appears, identified by the presence of a second hump in the particle size distribution (bimodal distribution not shown here). The part where the growth saturates gives a rate of $2 \mathrm{~nm} / \mathrm{min}$, consistent with a growth of the first NP generation by carbon deposition.

In the case of tungsten Nps, a new generation appears when $t>200 \mathrm{~s}$ and the coagulation saturation is not observed as shown in figure 3. Up to $200 \mathrm{~s}$, the dots are the average values, already given in figure 2 , in black. We have added from $120 \mathrm{~s}$ to $400 \mathrm{~s}$, 


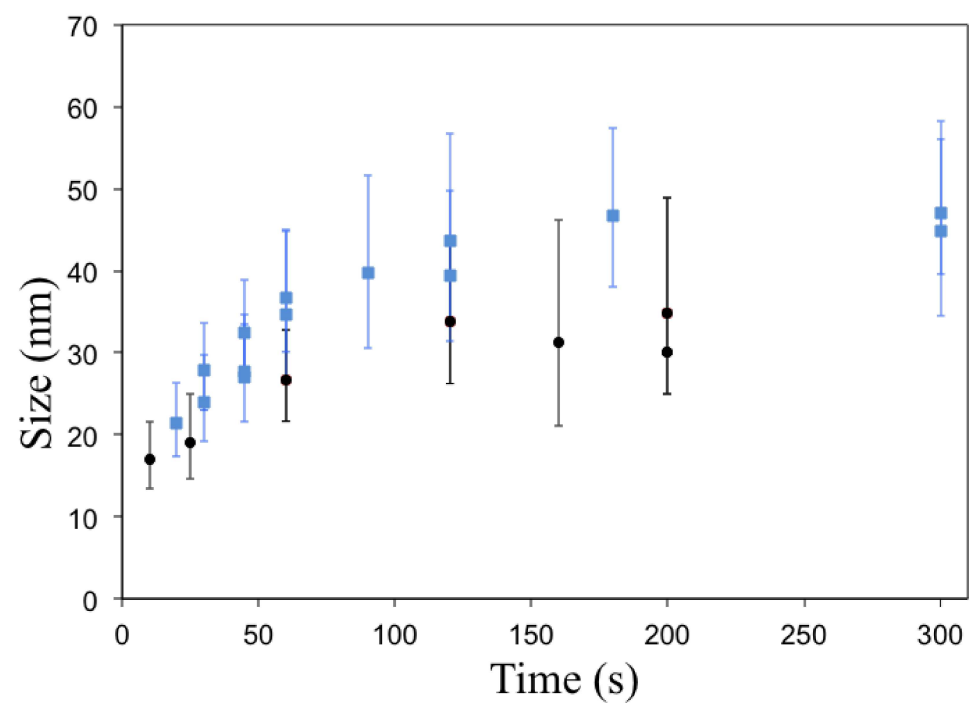

FiguRE 2. Size evolutions of the first generation of carbon (blue) and tungsten (black) nanoparticles as a function of plasma duration

the maxima of bi-modal distributions. Therefore, the dots at the top of figure 3 give the most probable size of the first NP generation.

If one assumes that all sputtered tungsten atoms participate to the NP growth by deposition with a sticking coefficient of 1 , a rough estimation of the growth rate, da/dt can be deduced from the tungsten flux expression: $\Gamma \sim 4 \rho / m_{W} \cdot \mathrm{d} a / \mathrm{d} t$, where $\rho$ is the tungsten mass density and $m_{W}$ the atomic mass. A sputtering yield of $3.2 \%$ (see reference, Kishor Kumar et al. (2013)) provides, $\Gamma \sim 10^{18} \mathrm{~m}^{-2} \mathrm{~s}^{-1}$ and a maximum growth rate by deposition, $\mathrm{d} a / \mathrm{d} t \sim 12 \mathrm{~nm} / \mathrm{min}$. This overestimated value being smaller than the one calculated with the upper dots of Figure $3(\sim 15 \mathrm{~nm} / \mathrm{min})$, we might conclude that the first generation of NPs grows mainly by a continuous coagulation.

The appearance time of the second generation presents a rather large dispersion. In contrast, for long plasma durations, both generations have similar growth rates. This result is correlated to the fact that small size particles are always present in the histograms, which indicates a continuous nucleation or formation of tungsten crystallites leading to a continuous coagulation.

\section{Evolution of discharge and plasma parameters, and discussion}

The presence of NPs, negativelly charged proportionally to their size, can be detected by strong modifications of the plasma and discharge parameters. Figures 4 a)-b) give the evolution of the discharge voltage $\mathrm{V}_{\mathrm{d}}$ (black) and the intensity of an Ar line (red) during the formation of carbon and tungsten NPs, in plasmas of $500 \mathrm{~s}$. In figure 4 -b) the intensity evolution of a tungsten line (blue) and the electron density evolution $\left(\mathrm{n}_{\mathrm{e}}\right.$ in green) measured by microwave interferometry are also presented. Signals show strong differences as a function of cathode materials.

When a graphite cathode is used, the increase of $\mathrm{V}_{\mathrm{d}}$ during $\sim 300 \mathrm{~s}$ is correlated to the NP size increase and consequently, to a progressive loss of free electrons in the plasma. The discharge current being fixed to a constant value, the compensation of the electron loss in the plasma is assured by a spontaneous increase of $\mathrm{V}_{\mathrm{d}}$ which enhances 


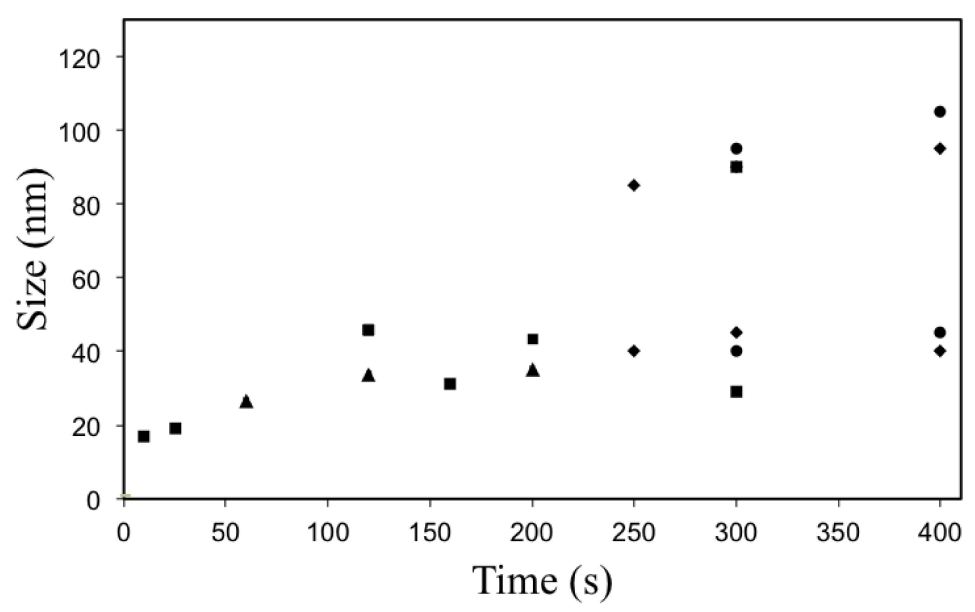

FIgURE 3. Size evolution of two generations of tungsten nanoparticles as a function of plasma duration. The various symbols represent sets of 3-4 measurements between two successive device opening.

the secondary electron (SE) emission at the cathode surface. Therefore the gas ionisation is also increased.

From $\mathrm{t} \sim 300 \mathrm{~s}$ to $\mathrm{t} \sim 440 \mathrm{~s}, \mathrm{~V}_{\mathrm{d}}$ saturates and then decreases until $\mathrm{t} \sim 460 \mathrm{~s}$ while the plasma emission decreases. This discharge behaviour is correlated to the NP cloud transport from the beginning of the negative glow (NG) located under the cathode sheath, towards the end of the NG, located above the anode sheath. This transport was first observed by laser light scattering by G. M. Jellum and D. B. Graves, in similar conditions (Jellum \& Graves 1990). Therefore, dust particles that are transported towards a region where the plasma density is smaller than near the cathode collect fewer electrons. In this situation, the discharge is easier to sustain $\left(\mathrm{V}_{\mathrm{d}}\right.$ saturation). This transport could also explain the coagulation saturation if one assumes that new nucleation can only take place in a dust free region (beginning of the NG) as it was observed in the void region of RF dusty plasmas ((Samsonov \& Goree 1999b; Mikikian et al. 2010; Cavarroc et al. 2008)). Hence, in such DC discharges, sputtered atoms which are emitted continuously could more efficiently give birth to a second generation of NPs at the beginning of the $\mathrm{NG}$, as the first generation of NPs is transported towards the end of the NG. In the last sequence $(>450 \mathrm{~s}), \mathrm{V}_{\mathrm{d}}$ increases again (as does the plasma emission) in a similar way as during the beginning of the discharge. This rise allows the compensation of electron losses due to the charging of the new NP generation.

When a tungsten cathode is used, after the breakdown $\mathrm{V}_{\mathrm{d}}$ rises from $\sim 500 \mathrm{~V}$ to $\sim 620 \mathrm{~V}$ in 3-4 s. At t $\sim 4 \mathrm{~s}, \mathrm{~V}_{\mathrm{d}}$ drops by $\sim 15 \mathrm{~V}$ (not visible in Figure 4-b due to the time scale), then follows a plateau within $\sim 40 \mathrm{~s}$ and a consequent decrease of $\sim 200 \mathrm{~V}$ during $150 \mathrm{~s}$. These successive behaviours of $\mathrm{V}_{\mathrm{d}}$ are correlated to the sudden appearance of a bright glow under the cathode center (appearance time $\sim 4 \mathrm{~s}$ ) and its expansion over the cathode surface within $150 \mathrm{~s}$. During this expansion, $\mathrm{n}_{\mathrm{e}}$ increases strongly. All this characteristics results from the sputtering of an oxide layer (bright glow appearance), starting in the cathode center. The cathode SE emission of pure tungsten being higher than that of tungsten oxide when the energy of ions and fast charge exchange neutral is lower than $100 \mathrm{eV}$, an increase of the ionisation occurs starting at $\mathrm{t} \sim 4 \mathrm{~s}$. Moreover, the tungsten 

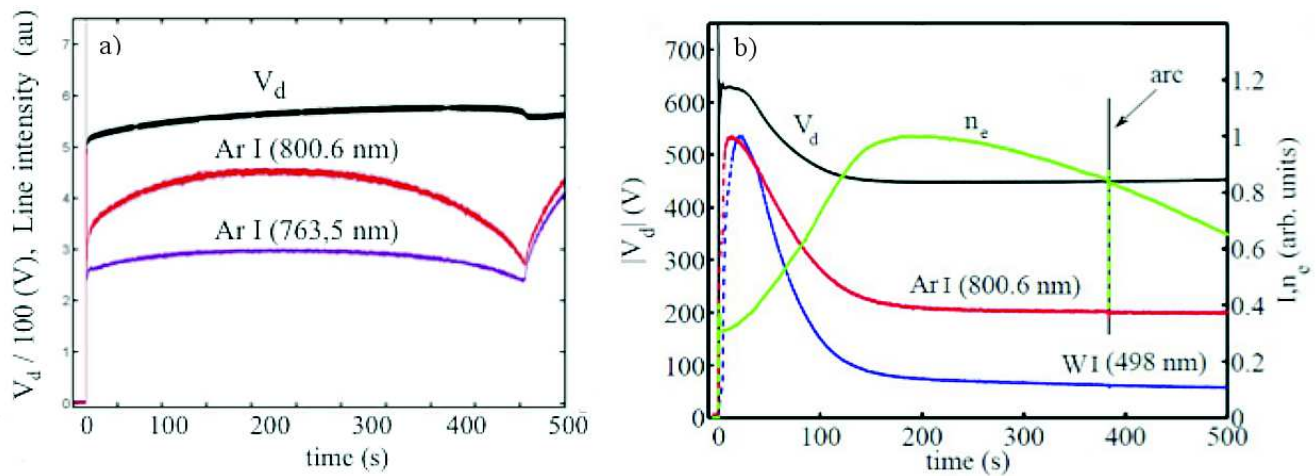

Figure 4. a) Evolution of the discharge voltage $V_{d}$ and the intensity of two argon lines b): Evolution of $\mathrm{V}_{\mathrm{d}}$, the intensity of argon and tungsten lines an the electron density $\left(\mathrm{n}_{\mathrm{e}}\right)$

ionisation potential being lower than that of argon $(7.86 \mathrm{eV}$ and $15.76 \mathrm{eV}$, respectively), an efficient $\mathrm{W}$ ionisation happens during the glow expansion over the cathode surface. Consequently, the electron density in the plasma increases. Because the discharge current is kept constant, $\mathrm{V}_{\mathrm{d}}$ decreases. This behaviour shows that there are conditions for which the charging mechanism of growing nanoparticles is not the leading process which drives the evolution of the plasma and discharge parameters.

In the last phase (>150 s), the charge carried by nanoparticles (two generations) becomes important and therefore the electron density decreases. As a consequence, $\mathrm{V}_{\mathrm{d}}$ must increase to sustain the ionisation process.

\section{Conclusion}

In this article, the formation of NPs from the sputtering of graphite and tungsten cathodes, in DC argon discharges is reported. Experiments were performed at fixed discharge currents and for similar sputtered carbon and tungsten fluxes. We show that carbon nanoparticles grow by coagulation and concomitant deposition up to the coagulation saturation. This saturation is explained by the appearance of a second NP generation, more efficiently feed by nucleation and coagulation, under the cathode sheath while the first NP generation is transported towards the anode region. Evolutions of the plasma and discharge parameters are correlated to the successive phases of growth and charging of the two NP generations. All the results confirm the existence of an electrostatic coupling between the nanoparticles and the discharge as expected in dusty plasmas. When a tungsten cathode is used, we show that the sputtering of a tungsten oxide layer at the cathode surface, dominates the early plasma (discharge) evolution. A progressive increase of the cathode secondary electron emission occurs and the injected tungsten atoms are ionised. These effects overcome the loss of free electrons due to the NP charging. No coupling is observed during this sequence. The influence of the loss of free electrons begin to appear during the formation of a second NP generation.

This work was supported by the French ANR contract, CRWTH No. ANR-09-BLAN0070-01-CRWTH.

\section{REFERENCES}

Annaratone, B M, Elskens, Y, Arnas, C, Antonova, T, Thomas, H M \& Morfill, G E 
2009 Agglomeration of mesoscopic particles in plasma. New Journal of Physics 11 (10), 103013.

Arnas, C., Michau, A., Lombardi, G., Couëdel, L. \& Kumar, K. Kishor 2013 Effects of the growth and the charge of carbon nanoparticles on dc discharges. Phys. Plasmas 20, 013705.

Arnas, C. \& Mouberi, A. A. 2009 Thermal balance of carbon nanoparticles in sputtering discharges. Journal of Applied Physics 105 (6), 063301.

Boufendi, L., Plain, A., Blondeau, J. Ph., Bouchoule, A., Laure, C. \& Toogood, M. 1992 Measurements of particle size kinetics from nanometer to micrometer scale in a low-pressure argon-silane radio-frequency discharge. Appl. Phys. Lett 60, 169.

Cavarroc, Marjorie, Mikikian, Maxime, Tessier, Yves \& Boufendi, Laifa 2008 Successive generations of dust in complex plasmas: A cyclic phenomenon in the void region. Physical Review Letters 100 (4), 045001.

Deschenaux, Ch, Affolter, A, Magni, D, Hollenstein, Ch \& Fayet, P 1999 Investigations of ch 4 , c 2 h 2 and c 2 h 4 dusty rf plasmas by means of ftir absorption spectroscopy and mass spectrometry. Journal of Physics D: Applied Physics 32 (15), 1876.

Dominique, C. \& ARnas, C. 2007 Cathode sputtering and the resulting formation of carbon nanometer-size dust. Journal of Applied Physics 101 (12), 123304.

Ganguly, B., Garscadden, A., Williams, J. \& Haaland, P. 1993 Growth and morphology of carbon grains. J. Vac. Sci. Technol. A 11 (4), 1119-1125.

Géraud-Grenier, Isabelle, Massereau-Guilbaud, Véronique \& Plain, André 2004 Characterization of particulates and coatings created in a $13.56\{\mathrm{MHz}\}$ radiofrequency methane plasma. Surface and Coatings Technology 187 (2-3), 336 - 342.

Jellum, G. M. \& Graves, D. B. 1990 Particulates in aluminum sputtering discharges. Journal of Applied Physics 67 (10), 6490-6496.

K., Kishor Kumar, CouËdel, L. \& Arnas, C. 2013 Growth of tungsten nanoparticles in direct-current argon glow discharges. Physics of Plasmas 20 (4), 043707.

Kovačević, E., Stefanović, I., Berndt, J., Pendleton, Y. J. \& Winter, J. 2005 A candidate analog for carbonaceous interstellar dust: Formation by reactive plasma polymerization. The Astrophysical Journal 623 (1), 242.

MatsoukAs, T. 1997 The coagulation rate of charged aerosols in ionized gases. J. Colloid Interf. Sci. 187, 474-483.

Mikikian, Maxime, Cavarroc, Marjorie, Couëdel, Lénaïc, Tessier, Yves \& Boufendi, LAÏFA 2010 Dust particles in low-pressure plasmas: Formation and induced phenomena. Pure Appl. Chem. 82, 1273.

Praburam, G. \& Goree, J 1995 Cosmic dust synthesis by accretion and coagulation. The Astrophysical Journal 441, 830.

Samsonov, D. \& Goree, J. 1999 a Instabilities in a dusty plasma with ion drag and ionization. Phys. Rev. E 59, 1047.

Samsonov, D. \& Goree, J. 1999 barticle growth in a sputerring discharge. J. Vac. Sci. Technol. A 17 (5), 2835.

Watanabe, Y 2006 Formation and behaviour of nano/micro-particles in low pressure plasmas. Journal of Physics D: Applied Physics 39 (19), R329.

Zeinert, A., Arnas, C., Dominique, C. \& Mouberi, A. 2008 Optical properties of carbonaceous nanoparticles produced in sputtering discharges. JOURNAL OF VACUUM SCIENCE \& TECHNOLOGY A 26 (6), 1450-1454. 